\title{
The Influence of RNA-Dependent RNA Polymerase 1 on Potato virus $Y$ Infection and on Other Antiviral Response Genes
}

\author{
Farshad Rakhshandehroo,, ${ }^{1,2}$ Minoru Takeshita, ${ }^{1,3}$ Julie Squires, ${ }^{1}$ and Peter Palukaitis ${ }^{1}$ \\ ${ }^{1}$ Scottish Crop Research Institute, Invergowrie, Dundee DD2 5DA, U.K.; ${ }^{2}$ Department of Plant Pathology, College \\ of Agriculture and Natural Resources, Science and Research Branch, Islamic Azad University, Tehran 14515-775, Iran; \\ ${ }^{3}$ Laboratory of Plant Pathology, Faculty of Agriculture, Division of Applied Genetic and Pest Management, Graduate School \\ of Kyushu University, 6-10-1 Hakozaki, Higashi-ku, Fukuoka 812-8581, Japan
}

Submitted 4 February 2009. Accepted 8 June 2009.

\begin{abstract}
The gene encoding RNA-dependent RNA polymerase 1 $(R D R 1)$ is involved in basal resistance to several viruses. Expression of the $R D R 1$ gene also is induced in resistance to Tobacco mosaic virus (TMV) mediated by the $N$ gene in tobacco (Nicotiana tabacum cv. Samsun NN) in an incompatible hypersensitive response, as well as in a compatible response against Potato virus $Y$ (PVY). Reducing the accumulation of NtRDR1 transcripts by RNA inhibition mediated by transgenic expression of a double-stranded RNA hairpin corresponding to part of the $R D R 1$ gene resulted in little or no induction of accumulation of $R D R 1$ transcripts after infection by PVY. Plants with lower accumulation of $R D R 1$ transcripts showed much higher accumulation levels of PVY. Reduced accumulation of NtRDRI transcripts also resulted in lower or no induced expression of three other antiviral, defense-related genes after infection by PVY. These genes encoded a mitochondrial alternative oxidase, an inhibitor of virus replication (IVR), and a transcription factor, ERF5, all involved in resistance to infection by TMV, as well as RDR6, involved in RNA silencing. The extent of the effect on the induced NtIVR and NtERF5 genes correlated with the extent of suppression of the NtRDRI gene.
\end{abstract}

Defense responses against infection by plant viruses involve a number of genes and either basal, constitutive expression or induced expression, the latter often associated with an activation by (indirect) interaction between the viral pathogen and a resistance $(R)$ gene (Lewsey et al. 2009; Palukaitis and Carr 2008). The best-studied system for the resistance response to a plant virus is still the $\mathrm{N}$-gene-mediated resistance response induced by Tobacco mosaic virus (TMV) in tobacco (Nicotiana tabacum cv. Xanthi nc or cv. Samsun NN) (Caplan and Dinesh-Kumar 2006; Gilliland et al. 2006), although many signaling components of the resistance response have been elucidated first in various resistance responses in Arabidopsis thaliana (Caplan and Dinesh-Kumar 2006; Kachroo 2006).

Infection of tobacco by TMV activates many defense-related genes (Caplan and Dinesh-Kumar 2006; Kachroo 2006;

Corresponding author: Peter Palukaitis; Fax: +44 1382 568578; E-mail: Peter.Palukaitis@scri.ac.uk

* The $\boldsymbol{e}$-Xtra logo stands for "electronic extra" and indicates that a supplemental table and a supplemental figure are published online.
Lewsey et al. 2009; Palukaitis and Carr 2008). These include genes encoding RNA-dependent RNA polymerase 1 (RdRp1, encoded by $R D R($ ), a mitochondrial alternative oxidase (AOX1) (Chivasa et al. 1997; Murphy et al. 1999), an inhibitor of virus replication (IVR) (Loebenstein and Akad 2006), and the transcription factor ERF5 (Fischer and Dröge-Laser 2004). $R D R I$ gene expression has been shown to affect accumulation of some viruses but not others (Xie et al. 2001; Yang et al. 2004; Yu et al. 2003). RDRl was shown not to be necessary for RNA silencing in A. thaliana (Yu et al. 2003) and is dysfunctional in $N$. benthamiana, where RNA silencing has been studied extensively (Yang et al. 2004), whereas RDR6 was shown to be important for RNA silencing in $N$. benthamiana $(\mathrm{Qu}$ et al. 2005; Schwach et al. 2005). RDRl was shown to be upregulated by salicylic acid (SA) (Xie et al. 2001) but in a pathway separate from the $A O X 1$ gene (Gilliland et al. 2003); the RDRI gene also was upregulated in an SA-independent pathway during a compatible infection (Xie et al. 2001; Yang et al. 2004). The AOX1 gene was activated by SA and was shown to be involved in resistance to various viruses but not other pathogens (Chivasa et al. 1997; Mayers et al. 2005; Naylor et al. 1998). IVR gene expression was activated only in $N$ gene cultivars of tobacco by TMV and apparently not by other viral pathogens although, once expressed, IVR protein could inhibit replication of other viruses (Akad et al. 1999; Gera and Loebenstein 1983; Gera et al. 1990). The ERF5 gene also was activated in $N$ gene tobacco by infection with TMV and was shown to be involved in local and systemic resistance to infection by TMV, but regulation of ERF5 expression was shown to be independent of the SA or jasmonic acid (JA) pathways (Fischer and Dröge-Laser 2004).

Although expression of some of the above genes was not observed after infection by TMV in a susceptible tobacco cultivar, little is known concerning the expression of defenserelated genes during infection by other compatible viral pathogen-host combinations. One of the exceptions is the RDRI gene, which was activated during a systemic infection by TMV in a susceptible tobacco cultivar (Xanthi nn). This gene also was shown to be involved in reducing virus accumulation and disease induced by infection with Potato virus $X$ (PVX) in tobacco (Xie et al. 2001), as well as a crucifer strain of TMV (TMV-cg) and Tobacco rattle virus (TRV) in A. thaliana (Yu et al. 2003). On the other hand, in $N$. benthamiana, where the expressed $R D R 1$ encodes a truncated RdRp1, transgenic expression of an intact $R D R l$ gene from Medicago truncatula reduced virus infection of three Tobamovirus spp. but not of 
PVX or Cucumber mosaic virus (CMV) (Yang et al. 2004). By contrast, inhibiting accumulation of $N$. benthamiana RDR6 gene transcripts by RNA silencing had no effect on infection by TRV but affected infection by PVX and Potato virus $Y$ (PVY); the effect on infection by TMV differed in the two reports (Qu et al. 2005; Schwach et al. 2005). In a recent report, RNA silencing of the homologue of the RDR6 gene in $N$. attenuata $(R D R 3)$ resulted in enhanced infection by two Tobamovirus spp. (Pandey et al. 2008a). Thus, RDR1 and RDR6 affect various groups of viruses differently, and the role of $R D R 1$ in basal defense against other viruses needs to be evaluated.

Here, we examined the effects of infection of tobacco by PVY, a member of a different taxonomic family from PVX, TRV, and the Tobamovirus spp. tested previously, on expression of the RDRl gene during a compatible virus-host interaction and also what effect reducing the accumulation of the $R D R 1$ gene transcripts had on infection by PVY. We also examined the effects of PVY infection on expression of several other defense-related genes in nontransformed as well as in $R D R 1$ transcript-silenced plants.

\section{RESULTS}

\section{Reducing $R D R 1$ transcript accumulation} enhances infection by PVY.

To determine whether RdRp1 was involved in the basal resistance to infection by PVY, the effect on expression of the $R D R l$ gene was assessed first during a systemic infection by
PVY in tobacco (N. tabacum cv. Samsun NN). Expression of the $R D R 1$ gene was not examined at earlier times postinoculation, because we wanted to examine what effect was prevalent still at a time after symptom appearance in the systemic leaves, rather than potential earlier transitory effects in the inoculated leaves. Tobacco plants were inoculated with PVY and, 7 days later, when systemic symptoms were clear, total RNA was extracted and the expression of the tobacco $R D R l$ gene was examined by semiquantitative reverse-transcription polymerase chain reaction (RT-PCR). The level of RDRl messenger $(\mathrm{m})$ RNA increased in noninoculated leaves after systemic infection (Fig. 1). This increase was much less than was observed in upper leaves after infection by TMV (Fig. 1), in which a hypersensitive response (HR) was produced in the inoculated leaves in 2 to 3 days, limiting infection to those leaves. Thus, the tobacco RDRl gene was induced by infection with PVY but this level of increased expression of $R D R I$ did not prevent systemic infection by PVY.

To determine whether expression of the RDRl gene had any effect on PVY infection, transgenic tobacco plants were produced with reduced accumulation of RNA transcripts of the NtRDRl gene. These transgenic plants expressed a 542-bp, double-stranded RNA, hairpin containing a ChsA intron under the control of the Cauliflower mosaic virus 35S RNA promoter, in which the hairpin RNA contained NtRDRl gene sequences from nucleotide 1,614 to 2,155 . Of 18 lines produced, two were used here, as representative of those lines containing a single insertion event (line R-9-3) versus two independent insertion events (line R-10-1), as determined by the segrega-

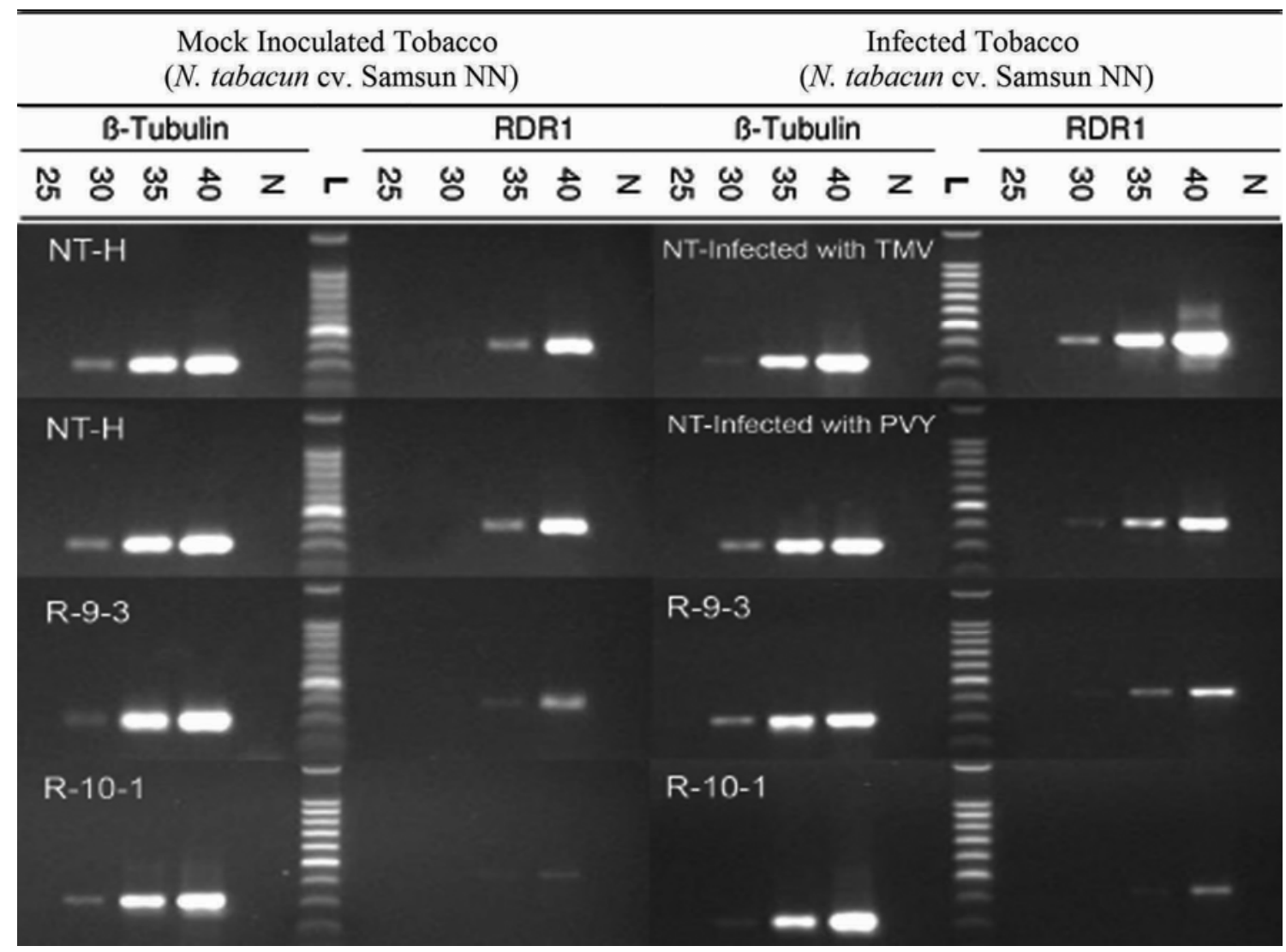

Fig. 1. Semiquantitative reverse-transcription polymerase chain reaction (PCR) for accumulation of transcripts of the gene encoding RNA-dependent RNA polymerase $1(R D R 1)$ from mock-inoculated and virus-inoculated transgenic and nontransformed tobacco plants. The accumulation of $R D R 1$ gene transcripts was assayed 1 week after either Tobacco mosaic virus (TMV) inoculation of nontransformed (NT) tobacco plants or Potato virus $Y$ (PVY) inoculation of nontransformed (NT) and transgenic tobacco plants (Samsun NN, lines R-9-3 and R-10-1) in which the expression of the RDRl gene had been reduced by RNAi. The levels of RDR1 messenger RNA accumulation are compared with the accumulation of the housekeeping gene $\beta$-tubulin. The numbers show the number of PCR cycles ( 25 to 40 ). $\mathrm{N}=$ negative PCR control (water used as the template). L = 100-bp DNA ladder. The amplified products for the partial RDRl and $\beta$-tubulin genes are 430 and $300 \mathrm{bp}$, respectively. 
tion ratios for germination of the $\mathrm{T} 1$ generation seed on plates containing the herbicide BASTA (data not shown). Both transgenic lines showed the presence of small interfering RNAs (siRNAs) specific to the RDRl gene, which were absent from control, nontransformed plants (Fig. 2).

Accumulation of transcripts of the $R D R l$ gene was shown to be reduced in both transgenic lines but to a greater extent in line R-10-1 than in line R-9-3 (Fig. 1), consistent with expectations based on the number of insertion events. Infection of these transgenic plants by PVY resulted in a slight but noticeable increase in the level of RDRl mRNA accumulation (Fig. 1 ), although the accumulation level was still much lower in plants of line R-10-1 than in either line R-9-3 or nontransformed plants. The level of siRNAs specific to RDRl also increased considerably after infection by PVY in line R-10-1 but not in line R-9-3 (Fig. 2), suggesting that transcripts of the $R D R 1$ gene were degraded more effectively in line $\mathrm{R}-10-1$ plants than in line R-9-3 plants. In parallel with these changes in the levels of accumulation of the $R D R l$ gene transcripts, the level of PVY RNA also increased during systemic infection in these lines, with plants of line R-10-1 containing a higher level of PVY RNA accumulation than plants of line R-9-3, and both lines containing considerably more PVY RNA than the mockinoculated plants (Fig. 3). Thus, reduction of the accumulation of the tobacco RDRl gene transcripts led to increased PVY accumulation. This indicates that the tobacco RdRp1 is involved

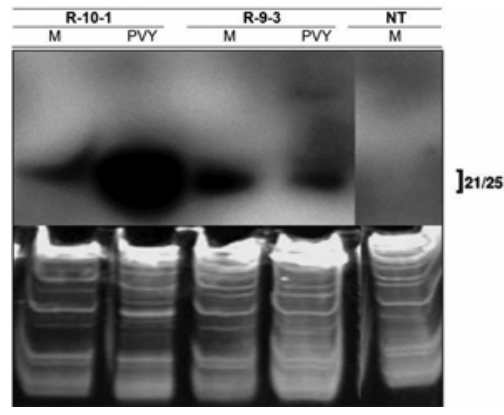

Fig. 2. Northern blot analysis of low molecular mass RNAs. Total RNA isolated 1 week after Potato virus $Y$ (PVY) inoculation was subjected to Northern blot hybridization analysis using digoxigenin-labeled RNA of the gene encoding RNA-dependent RNA polymerase 1 ( $R D R 1)$ as probe RNAs were extracted from plants of two $R D R 1$-silenced transgenic tobacco lines, R-9-3 and R-10-1, mock-inoculated (M) or infected by PVY, as well as from mock-inoculated (M), nontransformed tobacco plants (NT). The probe shows the accumulation of small interfering RNA produced from the $R D R 1$ genes and the RDRl transgenes. The size range of 21- to 25-nucleotide small RNAs is marked. The ethidium bromide staining of the RNA is shown underneath each lane to allow assessment of equal loading. in the basal defense mechanism against infection by PVY as it is against TMV and PVX (Xie et al. 2001). Although not presented here, similar results were obtained using transgenic tobacco line R-14-1 (moderately suppressed $R D R 1$ ) and line R5-1 (highly suppressed $R D R l$ ).

\section{Reduction of $R D R I$ gene transcript accumulation also affects expression of other defense-related genes.}

To determine whether infection by PVY affected transcription of other defense-related genes in nontransformed plants, we examined the level of accumulated mRNAs of the $I V R$, $A O X 1$, and ERF5 genes in mock-inoculated plants and in plants infected systemically with PVY. IVR gene expression was induced by infection with PVY, although the extent of induction was much less than was observed after infection for TMV (Fig. 4A), despite the fact that upper leaves assayed were infected by PVY but were not infected by TMV, which was localized by the HR. By contrast, ERF5 gene expression was induced to a much higher level by infection with PVY than by infection with TMV (Fig.4B), while AOX1 gene expression was induced to a similar extent by both TMV and PVY (Fig 4B). It is not known whether expression of AOX1 or ERF5 has any effects on infection by PVY, whereas it has been stated that IVR can inhibit PVY (Loebenstein and Akad 2006).

To determine whether reduction of the tobacco RDRl gene transcript accumulation had some effect on the expression of the IVR, ERF5, or $A O X 1$ genes before and after PVY infection, RNAs extracted from mock-inoculated and infected transgenic lines R-9-3 and R-10-1 were examined by RT-PCR at 7 days postinoculation. As in nontransformed plants, expression of neither the IVR nor the ERF5 genes could be detected in mock-inoculated transgenic plants; however, after infection by PVY, the expression of both genes was induced in plants of line R-9-3, with ERF5 induced to a lesser extent than in nontransformed plants (Fig. 4A and B). On the other hand, expression of neither gene could be detected in line R-10-1 plants (Fig. 4A and B). By contrast, a basal, constitutive expression of the AOX1 gene was observed in mock-inoculated plants of both transgenic lines, similar to the level observed in healthy nontransformed plants; however, in plants of both transgenic lines, the level of expression of the $A O X 1$ gene did not increase after infection by PVY, whereas expression of this gene did increase in PVY-infected, nontransformed plants (Fig. 4B). Thus, reduction of the tobacco RDRl gene transcript accumulation either reduced or prevented induced expression of three other antiviral, defense-related genes, and the extent of the effect on the induced NtIVR and NtERF5 genes correlated with the extent of reduction of the NtRDRl gene transcript accumulation.

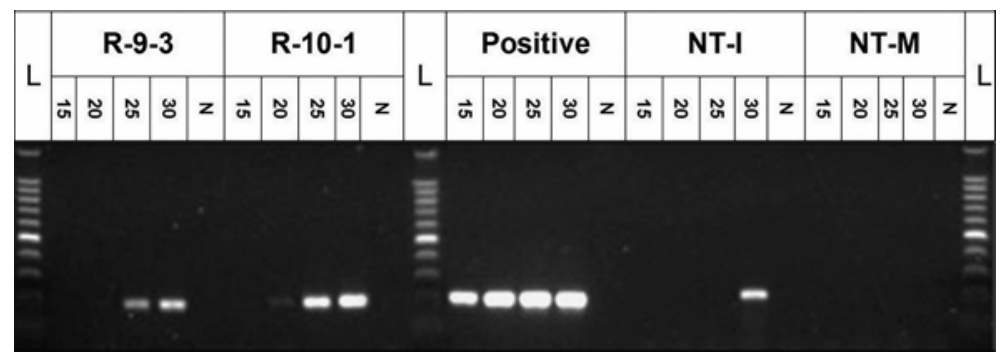

Fig. 3. Level of Potato virus $Y$ (PVY) RNA accumulation. Semiquantitative reverse-transcription polymerase chain reaction (PCR) of the capsid protein-encoding region of the PVY genome in RNAs extracted from mock-inoculated nontransformed (NT-M), PVY-inoculated nontransformed (NT-I), and PVYinoculated transgenic (lines R-9-3 and R-10-1) tobacco plants in which the expression of the gene encoding RNA-dependent RNA polymerase 1 (RDRI) has been reduced by RNAi. More PVY RNA is present in the transgenic plants than in the nontransformed plants. The numbers show the number of PCR cycles (15 to 30). $\mathrm{N}=$ negative PCR control (water used as the sample). Positive $=$ previously cloned PVY capsid-protein-encoding region cDNA at $70 \mathrm{ng} / \mu \mathrm{l}$ used as positive control sample, showing no further increase (saturation) after 20 cycles. $\mathrm{L}=100$-bp DNA ladder. The amplified product for the partial PVY sequence is $200 \mathrm{bp}$. 
The effect of PVY infection also was examined on the expression of the tobacco RDR6 gene, both in nontransformed plants and in transgenic plants silenced for expression of the $R D R 1$ gene. In nontransformed plants, there was a basal level of RDR6 gene expression in the mock-inoculated plants that was increased after infection by PVY as well as TMV (Fig. 5). In contrast, in mock-inoculated, transgenic tobacco plants of both lines R10-1 and R-9-3, the basal level of expression of RDR6 was reduced compared with that observed in mockinoculated, nontransformed plants, and the level of RDR6 gene expression did not increase after infection by PVY (Fig. 5) in either transgenic line. Thus, the expression of the RDR6 gene also was affected by reducing the tobacco $R D R 1$ gene transcript accumulation, although with a profile different from that of the expression of the RDRl gene (Fig. 1).

\section{DISCUSSION}

The increased expression of $R D R l$ after infection by PVY (Fig. 1) and TMV (Xie et al. 2001) during a compatible virushost interaction indicates that this gene is part of the basal defense mechanism in tobacco. This same trend also was observed recently in $N$. glutinosa infected by PVY and several other viruses (Liu et al. 2009). However, whereas the RDRl gene ex-
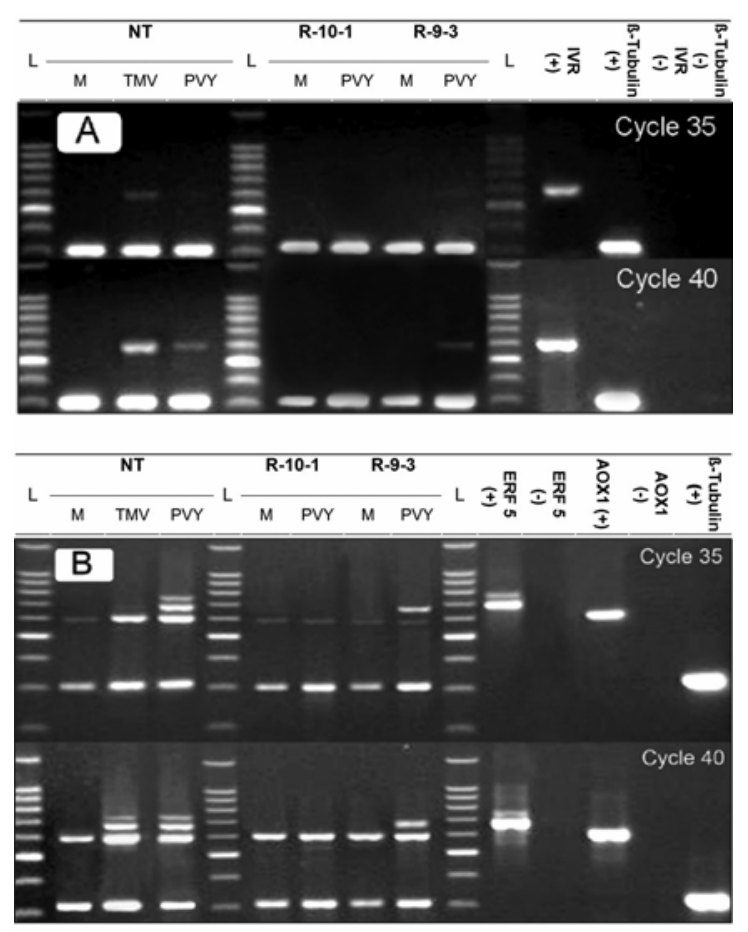

Fig. 4. Semiquantitative reverse-transcription polymerase chain reaction (RT-PCR) for expression of antiviral defense-related genes. The levels of expression of either $\mathbf{A}$, the inhibitor of virus replication (IVR) gene or $\mathbf{B}$, the mitochondrial alternative oxidase $(A O X 1)$ and ERF5 genes in RNAs extracted from tobacco (Samsun NN) 3 days after inoculation with Tobacco mosaic virus (TMV) and 1 week after inoculation with Potato virus $Y(\mathrm{PVY})$ in nontransformed (NT) plants, as well as 1 week after inoculation with PVY in transgenic lines R-9-3 and R-10-1, were determined by RT-PCR after 35 or 40 cycles of PCR. The defense gene accumulation levels are compared relative to the accumulation levels of the $\beta$-tubulin gene. $\mathrm{M}=$ mock-inoculated; TMV = inoculated with TMV; PVY = inoculated with PVY; IVR $(+)=$ positive control for IVR gene, amplified product $=581 \mathrm{bp}$; ERF5 $(+)=$ positive control for $E R F 5$ gene, amplified product $=700 \mathrm{bp} ;$ AOX $1(+)=$ positive control for $A O X$ gene, amplified product $=620 \mathrm{bp} ; \beta$-tubulin $(+)=$ positive control for $\beta$-tubulin gene; amplified product $=300 \mathrm{bp}$; IVR (-), AOX1 (-), ERF5 (-), and $\beta$-tubulin $(-)=$ negative controls (water serving as the template for the PCR); L = 100-bp DNA ladder. pression is induced after infection by some viruses, it does not successfully prevent systemic infection, although it apparently reduces the extent of virus accumulation (Fig. 3) (Xie et al. 2001). Interestingly, PVY infection also induced other genes shown previously to be involved in basal or induced resistance to TMV; for example, the $A O X 1$ gene, the $I V R$ gene, and the ERF5 gene (Fig. 4). Despite the induction of all of these genes involved in resistance to TMV infection, their combined effects were insufficient to prevent systemic infection by PVY although, when expression of all of these genes was reduced, virus infection was enhanced (Fig. 3).

In A. thaliana, RDRl gene expression was induced by both treatment with SA and infection with a compatible virus (TMV-cg) (Yu et al. 2003), which itself had little effect on induction of SA; whereas, in $N$. benthamiana, RDRl gene expression also was induced by treatment with SA and infection by TMV (Yang et al. 2004) and, in N. glutinosa, RDRl gene expression was induced by treatment with SA, JA, and several viruses (TMV, PVY, and CMV) (Liu et al. 2009). Based on these studies, it can be concluded that RdRp1 is involved in the basal resistance to infection by several viruses although, from the examples studied, RdRp1 was not able to prevent systemic infection by these viruses. Inhibiting the expression of the RDRl (Yu et al. 2003) or RDR6 (Dalmay et al. 2000) genes in A. thaliana did not inhibit viral-induced gene silencing, and inhibiting the expression of the AtRDR6 gene did not affect infection by most viruses tested (Dalmay et al. 2000; Mourrain et al. 2000). Those observations suggest that $R D R 1$ and $R D R 6$ may either function in a redundant manner or operate independently, but against different target viruses. In the case of tobacco, we observed that inhibition of accumulation of $R D R 1$ transcripts led to the reduction in the expression of $R D R 6$. This suggests that either $R D R l$ gene expression is epistatic to expression of $R D R 6$ or that there is some cross-talk between these genes in tobacco.

Although not examined directly, it is unlikely that the RDR6 mRNAs were targeted by the RDRl siRNAs for three reasons. i) Neither the differential basal expression in mockinoculated transgenic plants nor the differential induction of expression of $R D R 1$ after PVY infection of line R-9-3 versus line R-10-1 was mirrored by the expression profile of RDR6 (Fig. 1 versus Fig. 5). ii) If transcripts of the RDR6 gene were a target for the RDRl siRNAs, then the very large increase in $R D R 1$ siRNAs generated in line R-10-1 plants after

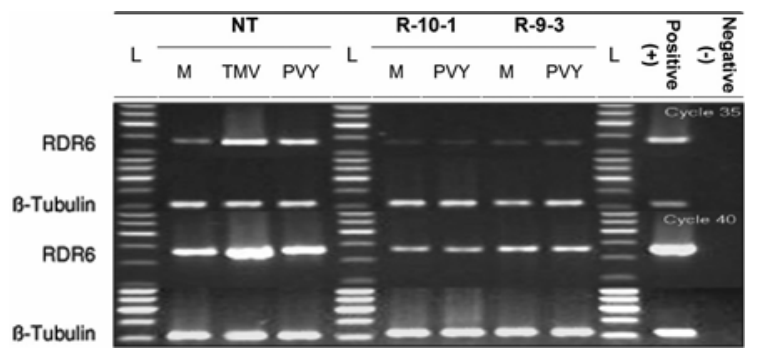

Fig. 5. Semiquantitative reverse-transcription polymerase chain reaction (RT-PCR) for expression of the RDR6 gene. The levels of expression of the RDR6 gene in RNAs extracted from tobacco (Samsun NN) 3 days after inoculation with Tobacco mosaic virus (TMV) and 1 week after inoculation with Potato virus $Y$ (PVY) in nontransformed (NT) plants, as well as 1 week after inoculation with PVY in transgenic lines R-9-3 and R-10-1, were determined by RT-PCR after 35 or 40 cycles of PCR. The RDR6 accumulation levels are compared relative to the accumulation levels of the $\beta$-tubulin gene. $\mathrm{M}=$ mock-inoculated; TMV = inoculated with TMV; PVY = inoculated with PVY; Positive $(+)=$ positive control for both the RDR6 gene and the $\beta$-tubulin gene, amplified products = 350 and $300 \mathrm{bp}$, respectively; Negative $(-)=$ negative controls (water serving as the template for the PCR); L = 100-bp DNA ladder. 
infection by PVY (Fig. 2) should have suppressed further the accumulation of RDR6 mRNAs in the same plants but, in fact, there was no decrease in the steady-state RDR6 transcript accumulation versus in the mock-inoculated line R-10-1 plants (Fig. 5). iii) A comparison of the nucleotide sequences of NtRDR1 and NtRDR6 in the 542 bp of NtRDR1 used for transformation of the plants reveals no regions of sequence identity larger than 14 contiguous nucleotides (one region), with other regions being in the range of 10 (one region), 8 (one), 7 (two), 6 (four), or 5 (four) contiguous nucleotides (Supplementary Fig. 1), although a potential effect on generating a functional microRNA could not be eliminated from sequence considerations alone but seems unlikely in lieu of points 1 and 2. Thus, the effects of decreasing accumulation of $R D R l$ transcripts and, presumably, $\mathrm{RdRp} 1$ protein had a secondary effect on the expression of $R D R 6$ and, presumably, the RdRp6 protein.

The reduction in accumulation of RNA transcripts of the $R D R 1$ and RDR6 genes alone probably was not the only cause of the enhanced accumulation of virus following infection by PVY (Fig. 3), because the reduction in RDRl transcript accumulation also resulted in reduced gene expression of $A O X 1$, $I V R$, and ERF5 (Fig. 4), all previously shown to be involved in either basal resistance $(A O X 1)$ or $N$-gene-mediated induction of resistance to TMV (AOXI, IVR, and ERF5) (Chivasa et al. 1997; Fischer and Dröge-Laser 2004; Gera et al. 1990). Thus, the effects, particularly seen in plants of line 10-1 (Figs. 1, 35 ), may be due to a combination of inhibition of all or some of these defense genes rather than to any single gene.

How does the RdRp1 affect expression of these other defense-related genes? A possible explanation comes from recent work in the Baldwin laboratory, which has shown that the RdRp1 of $N$. attenuata is involved in JA-mediated resistance to insect herbivory (Pandey and Baldwin 2007; Pandey et al. 2008b). This RdRp1 is involved in inducing the synthesis of JA immediately after feeding begins, as well as the synthesis of ethene, an inhibitor of JA, at a later time. JA is required for the synthesis of nicotine and this synthesis is inhibited by ethene (Pandey and Baldwin 2007; Pandey et al. 2008b; Winz and Baldwin 2001). These authors suggested that the RdRp1 functions through the small RNA-mediated degradation of mRNAs encoding other regulatory proteins inhibiting either the synthesis of JA and or the enzymes involved in the synthesis of nicotine; the change in the profile of the small RNAs derived from a number of JA synthesis and JA-response genes supports this model (Pandey and Baldwin 2007; Pandey et al. 2008b). In addition, both JA and SA stimulate RDRl gene expression in $N$. attenuata, even though these signaling phytohormones are antagonistic to each other (Jalali et al. 2006; Kazan and Manners 2008; Pandey and Baldwin 2007). Thus, the interactions between factors regulating $R D R 1$ gene expression and its various downstream targets are complex. In a similar manner, the tobacco RdRp1 may be involved in suppressing the expression of various regulatory molecules that prevent induction of other defense responses targeted against viruses and in directly affecting viral genomes. The latter may occur either by a small RNA-/Dicer-/AGO-mediated RNA degradation mechanism, as occurs with RdRp6 (Brodersen and Voinnet 2008; Eamens et al. 2008), or by producing antisense RNA to regions with important sequences of single-stranded, structural domains required for replication, subgenomic RNA production, or translation and preventing their expression. Identifying the factors that lead to RdRp1-dependent alteration in expression of various other defense-related genes should provide further mechanistic insights into the complex regulation of defense responses in plants.

\section{MATERIALS AND METHODS}

\section{Cloning of NtRDR1 and preparation \\ of transformation vector.}

RNA purified from N. tabacum cv. Xanthi-nc using the RNeasy mini kit (Qiagen, Crawley, U.K.) was used as a template for RT-PCR (as described below) using primers RDR1-1 and RDR1-2 to amplify a 1,631-bp fragment (nucleotides 1,400 to 3,030 , based on the sequence of the $N$. tabacum cv. Petit Havana SR1 RDR1 gene; AJ011576). The PCR fragment was ligated into the vector pSK and transformed into Escherichia coli using standard procedures. The 1,631-bp insert was sequenced and was identical to the sequence in the GenBank (AJ011576) from tobacco cv. Petit Havana SR1. Plasmid from the resulting clone was purified and used as a template for PCR amplification of the 542-bp fragment of the NtRDRI gene (nucleotides 1,614 to 2,155 based on AJ011576). The PCR reactions were done with primers RDR1-3 and RDR1-4 containing different terminal restriction sites, as described at the Chrom DB website, to facilitate ligation into the plant transformation vector pFGC5941 (GenBank accession no. AY310901), in two separate cloning steps, to construct the modified vector to express the inverted repeat RNA of the 542bp fragment, as also used by Schwach and associates (2005) for the same vector containing the NbRDR6 gene.

\section{Plant transformation and screening.}

The pFGC5941 plasmid containing the two repeats of the 542-bp NtRDRl sequence was electroporated into Agrobacterium tumefaciens (strain LBA4404) and transformed into leaf pieces of N. tabacum cv. Samsun NN as described by Horsch and associates (1985), with minor modification; for example, the transformants were regenerated on Murashige-Skoog (MS) medium plus naphthalene acetic acid at $0.1 \mu \mathrm{g} / \mathrm{ml}$ and 6-benzylaminopurine at $1 \mu \mathrm{g} / \mathrm{ml}$ using glufosinate ammonium selection (BASTA at $100 \mu \mathrm{g} / \mathrm{ml}$ and cefotaxime at $250 \mu \mathrm{g} / \mathrm{ml}$ ) at $22^{\circ} \mathrm{C}$. Shoots from the callus developing on the medium were transplanted onto the above medium without BASTA. The shoots large enough to subculture were transplanted onto MS medium plus IAA at $8.75 \mathrm{ng} / \mathrm{ml}$, kinetin at $30 \mathrm{ng} / \mathrm{ml}$, folic acid at $1 \mathrm{ng} / \mathrm{ml}$, and cefotaxime at $250 \mu \mathrm{g} / \mathrm{ml}$. Rooted plantlets were transferred to soil pots and grown in the greenhouse at $25^{\circ} \mathrm{C}$. All 18 transformant lines were screened by PCR using extracted genomic DNA and primer pairs 35S plus RDR1-4 and ChsA plus RDR1-3. Four independent NtRDR1-silenced lines (R-5, R-9, R-10, and R-14) were selected for subsequent experiments. The activity of the RNAi construct in the four lines at the T0 generation stage was verified in a Northern blot assay for the formation of NtRDRl gene-derived siRNA. Seed of each of the four selected $\mathrm{T} 0$ transgenic lines were collected and germinated on BASTA-containing MS medium to determine the segregation ratios and propagate the $\mathrm{T} 1$ generation plants (R-5-1, R-9-3, R-10-1, and R-14-1). The T2 generation transgenic plants used in the subsequent experiments were homozygous for the presence of the partial NtRDRl inverted repeat.

\section{Plant materials, virus inoculations, and growth conditions.}

Seed of nontransformed and T2 generation transgenic tobacco were germinated in soil and maintained under greenhouse conditions, (25 and $18^{\circ} \mathrm{C}$, day and night, respectively; $16 \mathrm{~h}$ of daylight), as were virus-inoculated plants. Two or three lower leaves of 4-week-old transgenic and nontransformed tobacco plants were inoculated evenly over the upper leaf surfaces with either PVY strain O or TMV strain U1 using Carborundum as an abrasive. The inocula were buffered extracts of infected tobacco plants $(3 \mathrm{ml}$ of phosphate-buffered saline, $\mathrm{pH} 7.6$, per 
$1 \mathrm{~g}$ of plant material). "Mock-inoculated" plants were inoculated with buffer alone. Four plants (two mock-inoculated and two virus-infected) of each line were assessed in each treatment, which was done three independent times.

\section{RNA extraction, cDNA synthesis, and PCR.}

Total RNA was extracted from $200 \mathrm{mg}$ of upper, noninoculated leaves from mock-inoculated as well as PVY- and TMVinfected transgenic and nontransformed plants, 1 week after inoculation, using the RNeasy mini kit (Qiagen) according to the manufacturer's protocol. In situ DNase treatment was performed using the RNase-Free DNase set (Promega UK, Southampton, U.K..) at the end of the extraction procedure. A twostep semiquantitative RT-PCR method was used to measure gene expression in the tobacco leaf samples. The (antisense) primers used are listed in Supplementary Table 1. cDNA synthesis was done using M-MLV reverse transcriptase (Promega) according to the manufacturer's protocol. For amplification of cDNAs corresponding to mRNAs, $1 \mu \mathrm{l}$ of cDNA product was amplified with 1 unit of GoTaq (Promega) in a $10-\mu$ l reaction containing the buffer provided by the manufacturer supplemented with $\mathrm{MgCl}_{2}$, whereas a $1 / 15$ dilution of $1 \mu \mathrm{l}$ of cDNA was used for amplification of PVY sequences using purified plant RNA as the template (Fig. 3). PCR was performed over a range of 15 to 30 cycles for amplification of PVY RNA or 25 to 40 cycles for amplification of plant mRNAs using the following parameters: 1 cycle of $95^{\circ} \mathrm{C}$ for $2 \mathrm{~min} ; 15$ to 40 cycles of $94^{\circ} \mathrm{C}$ for $1 \mathrm{~min}, 54^{\circ} \mathrm{C}$ for $30 \mathrm{~s}$, and $72^{\circ} \mathrm{C}$ for $40 \mathrm{~s}$; and $1 \mathrm{cy}-$ cle of $72^{\circ} \mathrm{C}$ for $10 \mathrm{~min}$. Each PCR assay for each plant sample was done two times. Each set of reactions always included a no-cDNA negative control and cDNA from an infected, nontransformed sample as a positive control. PCR products were detected by $2.1 \%$ agarose gel electrophoresis and ethidium bromide gel staining. The gels were scanned on a digital imaging system. The level of cDNA synthesis was estimated according to the PCR signal generated from the internal standard housekeeping gene $\beta$-tubulin amplified from 25 to 40 cycles starting with $1 \mu \mathrm{l}$ of the cDNA solution. Relative RT-PCR was performed using a published protocol (Spencer and Christensen 1999) to measure expression of the RDR1, IVR, AOX1, ERF5, and $R D R 6$ genes.

\section{Northern blotting of siRNA.}

For Northern blot analysis of siRNAs, RNAs were extracted from two fully expanded leaves of four or five either mockinoculated or PVY-infected 3.5-week-old transgenic tobacco plants harvested 1 week after PVY inoculation. RNA extraction, gel electrophoresis, electroblotting, and hybridization were all done as described previously (Canto et al. 2002) using the method of Llave and colleagues (2000). In-vitro-transcribed digoxigenin (DIG)-labeled RNA probes of a cloned fragment of $N t R D R 1$ were used to detect corresponding siRNA by incubation overnight at $42^{\circ} \mathrm{C}$ using Perfect Hyb hybridization buffer (Ambion, Applied Biosystems, Warrington, U.K.) following a $2-\mathrm{h}$ prehybridization in the same buffer. The membrane was washed and processed for detection of the DIGlabeled probe by autoradiography, as described by the manufacturer of the probe and detection system (Roche Diagnostics, Lewes, U.K.).

\section{ACKNOWLEDGMENTS}

We thank B.-S. Behboodi and H. R. Zamani Zadeh for their helpful suggestions and advice. The work was supported in part by a contract from The Scottish Government Rural and Environment Research and Analysis Directorate (RERAD) to the SCRI, and Grants-in-Aid for Scientific Research 18780030 from the Ministry of Education, Science, Sports and Culture, Japan, to M. Takeshita.

\section{LITERATURE CITED}

Akad, F., Teverofsky, E., David, A., Czosnek, H., Gidoni, D., Gera, A., and Loebenstein, G. 1999. A cDNA from tobacco codes for an inhibitor of virus replication (IVR)-like protein. Plant Mol. Biol. 40:969-976.

Brodersen, P., and Voinnet, O. 2008. Revisiting the principles if microRNA target recognition and mode of action. Nat. Rev. Mol. Cell Biol. 10:141-148.

Canto, T., Cillo, F., and Palukaitis, P. 2002. Generation of siRNAs by TDNA sequences does not require active transcription or homology to sequences in the plant. Mol. Plant-Microbe Interact. 15:1137-1146.

Caplan, J., and Dinesh-Kumar, S. P. 2006. Recognition and signal transduction associated with $R$ gene-mediated resistance. Page 73-98 in: Natural Resistance Mechanisms of Plants to Viruses. G. Loebenstein and J. P. Carr, eds. Springer, Dordrecht, The Netherlands.

Chivasa, S., Murphy, A. M, Naylor, M., and Carr, J. P. 1997. Salicylic acid interferes with tobacco mosaic virus replication via a novel, salicylhydroxamic acid-sensitive mechanism. Plant Cell 9:547-557.

Dalmay, T., Hamilton, A., Rudd, S., Angell, S., and Baulcombe, D. C. 2000. An RNA-dependent RNA polymerase gene in Arabidopsis is required for posttranscriptional gene silencing mediated by a transgene but not a virus. Cell 101:543-553.

Eamens, A., Wang, M. B., Smith, N. A., and Waterhouse, P. M. 2008. RNA silencing in plants: Yesterday, today, and tomorrow. Plant Physiol. 147:456-468.

Fischer, U., and Dröge-Laser, W. 2004. Overexpression of $N t E R F 5$, a new member of the tobacco ethylene response transcription factor family enhances resistance to Tobacco mosaic virus. Mol. Plant-Microbe Interact. 17:1162-1171.

Gera A., and Loebenstein, G. 1983. Further studies of an inhibitor of virus replication from tobacco mosaic virus-infected protoplasts of a local lesion responding cultivar. Phytopathology 73:111-115.

Gera, A., Loebenstein, G., Salomon, R., and Franck, A. 1990. An inhibitor of virus replication (IVR) from protoplasts of a hypersensitive tobacco cultivar infected with tobacco mosaic virus is associated with a $23 \mathrm{~K}$ protein species. Phytopathology 80:78-81.

Gilliland, A., Singh, D. P., Hayward, J. M., Moore, C. A., Murphy, A. M., York, C. J., Slator, J., and Carr, J. P. 2003. Genetic modification of alternative respiration has differential effects on antimycin A-induced versus salicylic acid-induced resistance to Tobacco mosaic virus. Plant Physiol. 132:1518-1528.

Gilliland, A., Murphy, A. M., and Carr, J. P. 2006. Induced resistance mechanisms. Pages 125-144 in: Natural Resistance Mechanisms of Plants to Viruses. G. Loebenstein and J. P. Carr, eds. Springer, Dordrecht, The Netherlands.

Horsch, R. B., Fry, J. E., Hoffman, N. L., Eichholz, D., Rogers, S. G., and Fraley, R. T. 1985. A simple and general method of transferring genes into plants. Science 279:1486-1487.

Jalali, B. L., Bhargava, S., and Kamble, A. 2006. Signal transduction and transcriptional regulation of plant defense responses. J. Phytopathol. 154:65-74.

Kachroo, P. 2006. Host gene-mediated virus resistance mechanisms and signaling in Arabidopsis. Pages 147-164 in: Natural Resistance Mechanisms of Plants to Viruses. G. Loebenstein and J. P. Carr, eds. Springer, Dordrecht, The Netherlands.

Kazan, K., and Manners, J.M. 2008. Jasmonate signaling: Toward an integrated view. Plant Physiol. 146:1459-1468.

Lewsey, M., Palukaitis, P., and Carr, J. P. 2009. Plant-virus interactions: Defence and counter-defence. Pages 134-176 in: Annual Plant Reviews, Volume 34, Molecular Aspects of Plant Disease Resistance. J. Parker, ed. Wiley-Blackwell, Oxford.

Liu, Y., Gao, Q. Q., Wu, B., Ai, T., and Guo, X. Q. 2009. NgRDR1, an RNAdependent RNA polymerase isolated from Nicotiana glutinosa, was involved in biotic and abiotic stress. Plant Physiol. Biochem. 47:359-368.

Llave, C., Kasscchau, K. D., and Carrington, J. C. 2000. Virus-encoded suppressor of posttranscriptional gene silencing targets a maintenance step in the silencing pathway. Proc. Natl. Acad. Sci. U.S.A. 97:1340113406.

Loebenstein, G., and Akad, F. 2006. The local lesion response. Pages 99124 in: Natural Resistance Mechanisms of Plants to Viruses. G. Loebenstein and J. P. Carr, eds. Springer, Dordrecht, The Netherlands.

Mayers, C. N., Lee, K.-C., Moore, C. A., Wong, S.-K., and Carr, J. P. 2005. Salicylic acid-induced resistance to Cucumber mosaic virus in squash and Arabidopsis thaliana: Contrasting mechanisms of induction and antiviral action. Mol. Plant-Microbe Interact. 18:428-434.

Mourrain, P., Beclin, C., Elmayan, T., Feuerbach, F., Godon, C., Morel, J. B, Jouette, D., Lacombe, A. M., Nikic, S., Picault, N., Remoue, K., Sanial, M., Vo, T. A., and Vaucheret, H. 2000. Arabidopsis SGS2 and SGS3 genes are required for posttranscriptional gene silencing and natural virus resistance. Cell 101:533-542. 
Murphy, A. M., Chivasa, S., Singh, D. P., and Carr, J. P. 1999. Salicylic acid induced resistance to viruses and other pathogens: A parting of the ways? Trends Plant Sci. 4:155-160.

Naylor, M., Murphy, A. M., Berry, J. O., and Carr, J. P. 1998. Salicylic acid can induce resistance to plant virus movement. Mol. Plant-Microbe Interact. 11:860-868.

Palukaitis, P., and Carr, J. P. 2008. Plant resistance to viruses. J. Plant Pathol. 90:153-171.

Pandey, S. P., and Baldwin, I. T. 2007. RNA-directed RNA polymerase 1 (RdR1) mediates the resistance of Nicotiana attenuata to herbivore attack in nature. Plant J. 50:40-53.

Pandey, S. P., Gaquerel, E., Gase, K., and Baldwin, I. T. 2008a. RNA-directed RNA Polymerase3 from Nicotiana attenuata is required for competitive growth in natural environments. Plant Physiol. 147:1212-1224.

Pandey, S. P., Priyanka, P., Gase, K., and Baldwin, I. T. 2008b. Herbivoryinduced changes in the small-RNA transcriptome and phytohormone signaling in Nicotiana attenuata. Proc. Natl. Acad. Sci. U.S.A. 105:4559-4564.

Qu, F., Ye, X., Hou, G., Sato, S., Clemente, T. E., and Morris, T. J. 2005. RDR6 has a broad-spectrum but temperature dependent antiviral defense role in Nicotiana benthamiana. J. Virol. 79:15209-15217.

Schwach, F., Vaistij, F. E., Jones, L., and Baulcombe, D. C. 2005. An RNA-dependent RNA polymerase prevents meristem invasion by $\mathrm{Po}$ tato virus $X$ and is required for the activity but not the production of a systemic silencing signal. Plant Physiol. 138:1842-1852.

Spencer, W. E., and Christensen, M. J. 1999. Multiplex relative RT-PCR method for verification of differential gene expression. BioTechniques 27:1044-1052.

Winz, R. A., and Baldwin, I. T. 2001. Molecular interactions between the specialist herbivore Manduca sexta (Lepidoptera, Sphingidae) and its natural host Nicotiana attenuata. IV Insect-induced ethylene reduces jasmonate-induced nicotine accumulation by regulating putrescine $\mathrm{N}$ methyltransferase transcripts. Plant Physiol. 125:293-307.

Xie, Z., Fan, B., Chen, C., and Chen, Z. 2001. An important role of an inducible RNA-dependent RNA polymerase in plant antiviral defense. Proc. Natl. Acad. Sci. U.S.A. 98:6516-6521.

Yang, S.-J., Carter, S. A., Cole, A. B., Cheng, N.-H., and Nelson, R. S. 2004. A natural variant of a host RNA-dependent RNA polymerase is associated with increased susceptibility to viruses by Nicotiana benthamiana. Proc. Natl. Acad. Sci. U.S.A. 101:6297-6302.

Yu, D., Fan, B., MacFarlane, .S. A., and Chen, Z. 2003. Analysis of the involvement of an inducible Arabidopsis RNA-dependent RNA polymerase in antiviral defense. Mol. Plant-Microbe Interact. 16:206-216.

\section{AUTHOR-RECOMMENDED INTERNET RESOURCE}

Chrom DB website: www.chromdb.org 